\title{
NEW, SIMPLE AND EXPRESS DETERMINATION OF LAMOTRIGINE IN TABLETS BY USING DIAZOLE RED 2J
}

\author{
Kateryna Miedviedieva, Svitlana Vasyuk, Alla Korzhova, Ivan Pavljuk
}

Epilepsy is considered one of the most common chronic neurological diseases among humans. Lamotrigine is an effective new-generation anticonvulsant, which is widely introduced to the pharmaceutical market by various drug manufacturers. That is why the urgent aim for pharmaceutical analysis is developing of high precision, valid, accessible and quantitative methods for lamotrigine in pharmaceuticals.

The aim of the work is to study the optimal conditions for the reaction between lamotrigine and diazole red $2 \mathrm{~J}$, to define the coefficients of stoichiometric relationships in the "pharmaceutical substance - reagent" system and to develop a valid, sensitive and easy-to-follow technique for the quantitative determination of lamotrigine in pharmaceutical forms.

Material and methods. As reagent and solvent, diazole red $2 \mathrm{~J}$ of AR grade and acetone of AR grade were used. Analytical equipment: Specord 200 spectrophotometer, ABT-120-5DM electronic scales, Elmasonic E 60H ultrasonic bath and measuring glassware of A class.

Results. A new spectrophotometric method for the quantitative determination of lamotrigine in four pharmaceutical formulations based on interaction with diazole red $2 \mathrm{~J}$ in acetone medium has been developed. The proposed method is valid according to such validation characteristics as linearity, precision, intra-laboratory precision, accuracy, application range and robustness. The subordination to Behr's law is in the range of concentrations of 2.20-3.36 $\mathrm{mg} / 100 \mathrm{ml}$. The LOD and LOQ values based on the values of the calibration line were $0.00450 \%$ and $0.0138 \%$ respectively. It was found that the studied coloured solutions are stable for at least $60 \mathrm{~min}$ and fluctuations in the amount of added red diazole $2 J$ solution within $\pm 10 \%$ do not significantly affect the value of optical density. The coefficients of stoichiometric ratios between the components of the "lamotrigine - diazole red $2 J$ " reaction mixture were defined by three methods and are 1:1. The predicted complete uncertainty of the results of analysis for quantitative determination of lamotrigine in the pharmaceutical form (2.2\%) does not exceed the maximum allowable uncertainty for the technique (3.2\%) and meets the SPhU requirements.

Conclusions. According to the experimental data, the technique can be correctly reproduced and it is suitable for using in laboratories of the State Inspection for Quality Control of Medicines and QCD of the chemicopharmaceutical enterprises Keywords: spectrophotometry, analysis, lamotrigine, diazole red 2J, validation studies, Ukrainian Pharmacopeia

How to cite:

Miedviedieva, K., Vasyuk, S., Korzhova, A., Pavljuk, I. (2022). New, simple and express determination of lamotrigine in tablets by using diazole red 2J. ScienceRise: Pharmaceutical Science, 1 (35), 44-51. doi: http://doi.org/10.15587/1729-4061.2022.253542

(C) The Author(s) 2022

This is an open access article under the Creative Commons CC BY license hydrate

\section{Introduction}

At a global scale, one of the most common neurological diseases is epilepsy, which often leads to serious consequences. As a result, complex diagnostics and longterm treatment are needed. Currently, generally accepted standards for the treatment of this disease are already developed, compliance with which can significantly increase the effectiveness of treatment and improve the quality of patients' life. Lamotrigine (6-(2,3-dichlorophenyl)-1,2,4-triazine-3,5-diamine) is one of the most effective new-generation anticonvulsants, which is widely introduced to the pharmaceutical market by various drug manufacturers. For this reason, the confirmation of the quality of pharmaceutical drugs containing lamotrigine is subject to requirements which need accurate, reliable and inexpensive methods of quantitative analysis.
The British Pharmacopoeia (BP) recommends determining lamotrigine in a substance by non-aqueous titration using chloric acid in anhydrous acetic acid medium, with potentiometric fixation of the titration endpoint [1]. Despite the high accuracy of titrimetric methods of analysis for the quantitative determination of pharmaceutical drugs, it is the instrumental methods of analysis that are most often used, as more sensitive. Chromatographic methods of analysis are widely used to determine lamotrigine in biological fluids. Methods of analysis of high-performance liquid chromatography (HPLC) (in plasma [2, 3], in serum [4, 5], in rat plasma and brain [6]), thin-layer chromatography (TLC) [7] and gas chromatography (GC) [8] for the determination of lamotrigine in biological samples are described, as well as methods of capillary electrophoresis [9], HPLC and GC [10], ${ }^{1} \mathrm{H}-\mathrm{NMR}$ determination [11], TLC and planar 
chromatography in pharmaceutical forms. Information is provided on some spectrophotometric techniques for the determination of lamotrigine in the UV- (in pure form and in dosage forms [12], a first-order derivative UV method [13], spectrophotometry in the UV region after procedure of extraction [14]) and visible regions of the spectrum (using sulfophthalein dyes $[15,16]$ or 4(dimethylamino)benzaldehyde in acid medium [17] to give colouring products). Some of the provided methods are characterized by low sensitivity or selectivity, difficult to perform and require expensive equipment; others (for example, extractive spectrophotometric techniques) are timeconsuming, require additional stages of sample preparation, and in some cases inaccessible reagents are used. Thus, the advisability of developing new, simple, and valid methods for the quantitative determination of lamotrigine in pharmaceutical forms is beyond any doubt.

The aim of the work is to study the optimal conditions for the reaction between lamotrigine and diazole red $2 \mathrm{~J}$, to define the coefficients of stoichiometric relationships in the "pharmaceutical substance - reagent" system and to develop a valid, sensitive and easy-tofollow technique for the quantitative determination of lamotrigine in pharmaceutical forms.

\section{Planning of the research} ed purpose:

The following tasks are set, according to the stat-

1. Investigate the factors that may affect the speed and completeness of the reaction path, namely the amount of reagent added, reaction time and temperature.

2. Calculate the sensitivity data of this reaction and determine the stoichiometry between the components of the "lamotrigine - diazole red $2 \mathrm{~J}$ " reaction mixture.

3. Develop the technique for the quantitative determination of lamotrigine and apply it to the analysis of pharmaceutical forms.

4. Validate the developed method following the requirements of the $\mathrm{SPhU}$.

The sequence of tasks is given in Fig. 1.

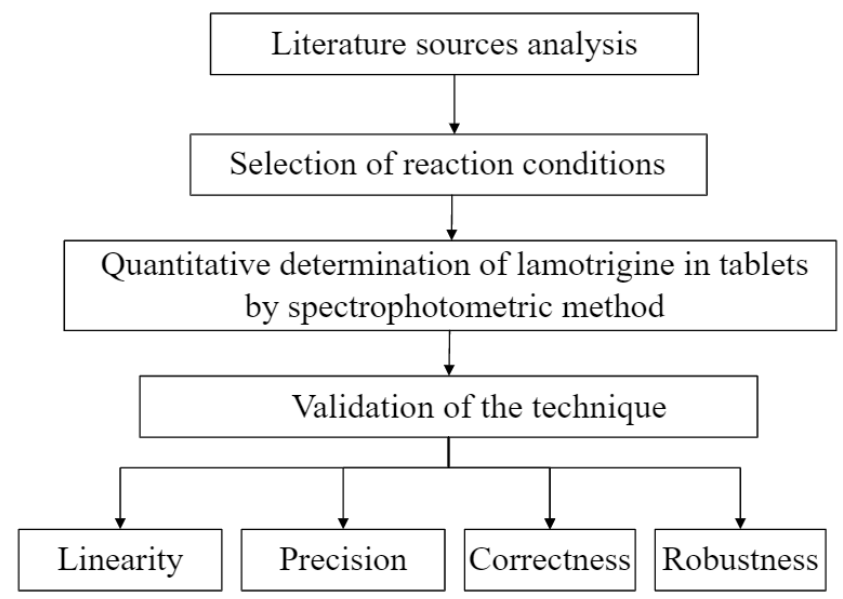

Fig. 1. Planning of the research

\section{Materials and methods}

Objects of study, solvents and equipment

The following was used to perform the experiment: lamotrigine substance (UM/191/08/18M); pharma- ceutical drugs - "Epileptal" tablets with 0.05 and $0.1 \mathrm{~g}$ of lamotrigine (Farmak, Ukraine) of 40619 and 71019 series respectively, "Lamotrin" tablets with $0.1 \mathrm{~g}$ of lamotrigine (Acino, Switzerland) of 751119 series, and "Lamictal" tablets with $0.1 \mathrm{~g}$ of lamotrigine (GlaxoSmithKline, Great Britain) of 121493 series.

As reagent and solvent, diazole red $2 \mathrm{~J}$ ( $\mathrm{p}$ nitrophenyldiazoniumboronfluoride) of AR grade and acetone of AR grade were used.

Analytical equipment: Specord 200 spectrophotometer, ABT-120-5DM electronic scales, Elmasonic E $60 \mathrm{H}$ ultrasonic bath and measuring glassware of A class.

\section{Results}

General technique for the quantitative determination of lamotrigine

An aliquot part $(0.00028 \mathrm{~g})$ of acetone solution of lamotrigine is placed into a $10.00 \mathrm{ml}$ measuring flask, treated with $1.00 \mathrm{ml}$ of $0.070 \%$ acetone solution of diazole red $2 \mathrm{~J}$, and mixed. The resulting solution is kept for 15 minutes at room temperature and brought up to the mark with acetone. The absorption of the analyzed solution is measured against the reference solution that does not contain the analyzed substance, at $370 \mathrm{~nm}$. Standard solution of lamotrigine $(0.0280 \%)$ and reagent solution $(0.070 \%)$ are prepared by dissolving the accurately weighed portion in acetone.

\section{Determination of lamotrigine in tablets}

While determining lamotrigine in tablets, the accurately weighed portion of tableting mass (approximately $0.0250 \mathrm{~g}$ ) is placed into a $50.00 \mathrm{ml}$ measuring flask, added with $10 \mathrm{ml}$ of acetone, and the tableting mass is being dissolved using an ultrasonic bath for 5 minutes. Then, it is brought to the mark with acetone and mixed. The resulting solution is filtered using a paper filter, previously casting away the first portions of filtrate. $1.00 \mathrm{ml}$ of the resulting solution is placed into a $10.00 \mathrm{ml}$ measuring flask, treated with $1.00 \mathrm{ml}$ of $0.070 \%$ acetone solution of red diazole $2 \mathrm{~J}$ and mixed. The resulting reaction mixture is kept for 15 minutes at room temperature and brought up to the mark with acetone. Simultaneously, an experiment with the work standard is performed. The calculation of the active substance content in one tablet is carried out by the method of standard according to formulae [18].

The results of analytical reactions are influenced by many factors, so it is possible to objectively define optimal conditions for quantitative spectral analysis only after performing preliminary experimental studies. At the stage of solvent selection, first of all, the solubility of the determinate and reagent, as well as maximum values of absorption of the resulting solutions were taken into account. It was found that the reagent interacts with lamotrigine in acetone medium with the formation of a colored product with a maximum of optical density at $370 \mathrm{~nm}$. It was also found that keeping the reaction mixture for a certain period of time on the day before bringing it up to the mark with the solvent in measuring flasks increases the value of optical density. Therefore, the optimal amount of reagent and the time of keeping the reaction mixture at room temperature $\left(18-25^{\circ} \mathrm{C}\right)$ were defined experimentally, according to the maximum values of optical density, as shown in Fig. 2. 

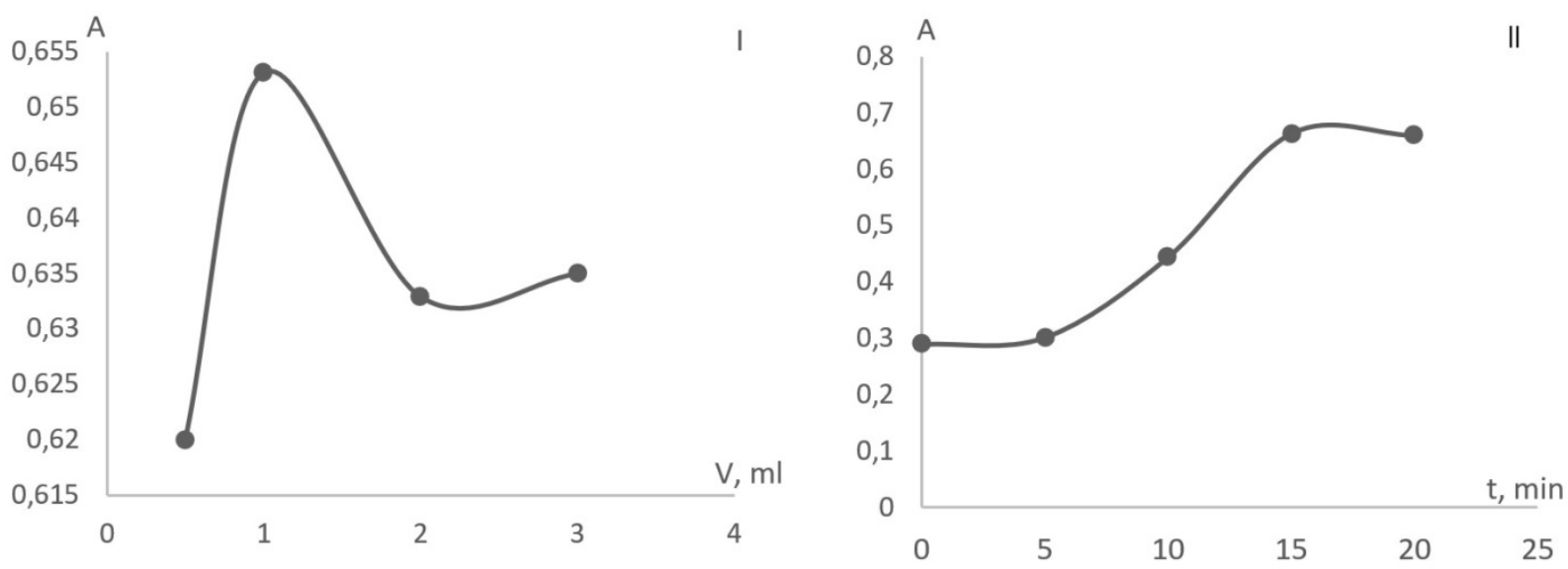

Fig. 2. I - Dependence of optical density on the amount of $0.070 \%$ solution of diazole red $2 \mathrm{~J}$; II - on the time of keeping the reaction mixture at room temperature

Thus, the color intensity of the interaction products of the reaction of diazole red $2 \mathrm{~J}$ with lamotrigine depends on the solvent, the reagent solution concentration and the time of the reaction mixture retention before bringing up to the nominal content of the measuring flask with the solvent.

Under optimal conditions, the subordination to Behr's law is in the range of concentrations of 2.20 $3.36 \mathrm{mg} / 100 \mathrm{ml}$.

The experimentally defined optimal conditions for the reaction of lamotrigine with diazole red $2 \mathrm{~J}$ are taken as the basis for the development of spectrophotometric techniques for the quantitative determination of lamotrigine in pharmaceutical forms.

Defining the stoichiometry between the components of the "lamotrigine - diazole red $2 J$ " reaction mixture

For a deeper and more detailed study of photometric reaction behaviour, stoichiometric relations were defined between the components of the "lamotrigine diazole red $2 \mathrm{~J}$ " reaction mixture.

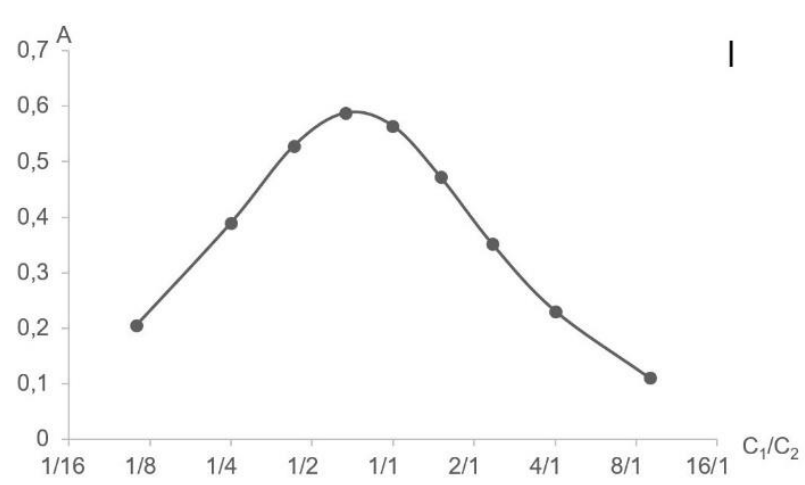

Stoichiometry is based on the laws of conservation of mass, equivalents, constancy of composition, and definite proportions. All stoichiometry laws are attributed to the atomic-and-molecular structure of matter. Subsequently, stoichiometry is used in calculations related to the formulae of substances and finding the theoretically possible yield of reaction products.

Therefore, the coefficients of stoichiometric ratios were defined by three methods, namely, by the method of continuous changes (the method of isomolar series), by the method of saturation (the method of molar ratios) and by the method of relative yield (the Starik - Barbanel method) [18].

The method of continuous changes is based on determining the ratios of isomolar concentrations of reactants, which corresponds to the maximum yield of compounds that are formed. Thereat, the curve of dependence of the reaction product yield on the composition of the solution is characterized by an extreme point, the position of which is associated with the stoichiometric coefficients $\mathrm{m}$ and $\mathrm{n}$ of the reaction product $\mathrm{M}_{\mathrm{m}} \mathrm{R}_{\mathrm{n}}$, as shown in Fig. 3 .

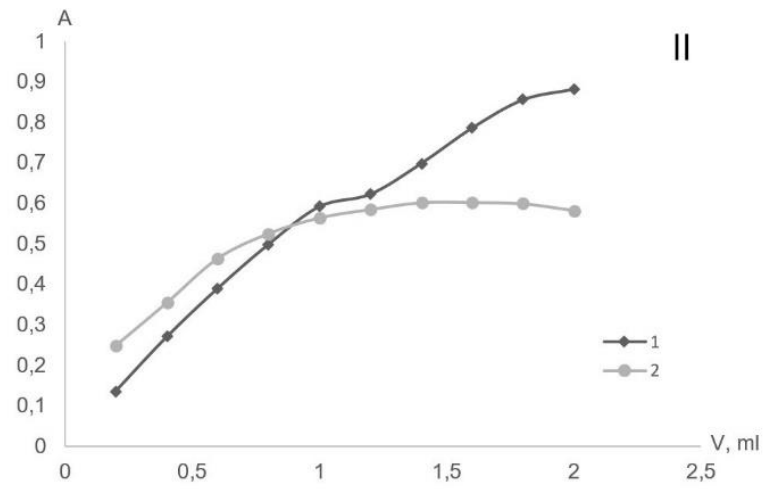

Fig. 3. I - Graph of the dependence of optical density on the composition of isomolar solution $\left(\mathrm{C}_{1}-0.001 \mathrm{M}\right.$ diazole red $2 \mathrm{~J}$ solution, $\mathrm{C}_{2}-0.001 \mathrm{M}$ lamotrigine solution) at $\lambda_{\max }=370 \mathrm{~nm}$; II - Saturation curves: 1 - lamotrigine at a constant concentration of diazole red $2 \mathrm{~J}(1.00 \mathrm{ml}$ of $0.001 \mathrm{M}$ solution $) ; 2$ - diazole red $2 \mathrm{~J}$ at a constant concentration of lamotrigine ( $1.00 \mathrm{ml}$ of $0.001 \mathrm{M}$ solution) at $\lambda_{\max }=370 \mathrm{~nm}$

To perform the analysis, the solutions of reagent and analyzed pharmaceutical drug of the same molar concentration were prepared and mixed in antibate ratios, while the total volume of the solution remained unchanged. In this case, the cumulative amount of moles of both components in the total volume of the solution remains constant.

The essence of the method of saturation is to define the dependence of optical density value on the con- 
centration of one of the components at a constant concentration of the other component and vice versa. As shown in Fig. 3, the ratio is defined using a perpendicular line drawn from the intersection of two curves.

The reactions were performed according to the developed techniques. Measurement of the absorption of resulting solutions was performed at the selected analytical wavelength. According to the obtained data, graphs of the dependence of the optical density value on the number of added components were plotted.

The relative yield method is based on using the equation of the algebraic sum of stoichiometric reaction coefficients, which characterize the composition of the equilibrium mixture at the point of maximum relative yield.
To perform the experiment, two series of solutions are prepared, in one of which the reagent concentration changes under the condition of the constant concentration of pharmaceutical drug, and in the other one, on the contrary, the reagent concentration remains constant (as in the saturation method). According to the obtained data, the relative yield curves are plotted in $\Delta \mathrm{A} / \mathrm{C}_{\mathrm{R}}-\Delta \mathrm{A} / \Delta \mathrm{A}_{\max }$ coordinates.

As shown in Fig. 4, the absence of a maximum on the curve of the relative reaction product yield indicates that the stoichiometric coefficient of the variable concentration component is equal to one. As can be seen from the graph, on both curves of the relative yield of "lamotrigine - diazole red $2 \mathrm{~J}$ " reaction product, maxima are absent, which indicates an interaction at 1:1 ratio.

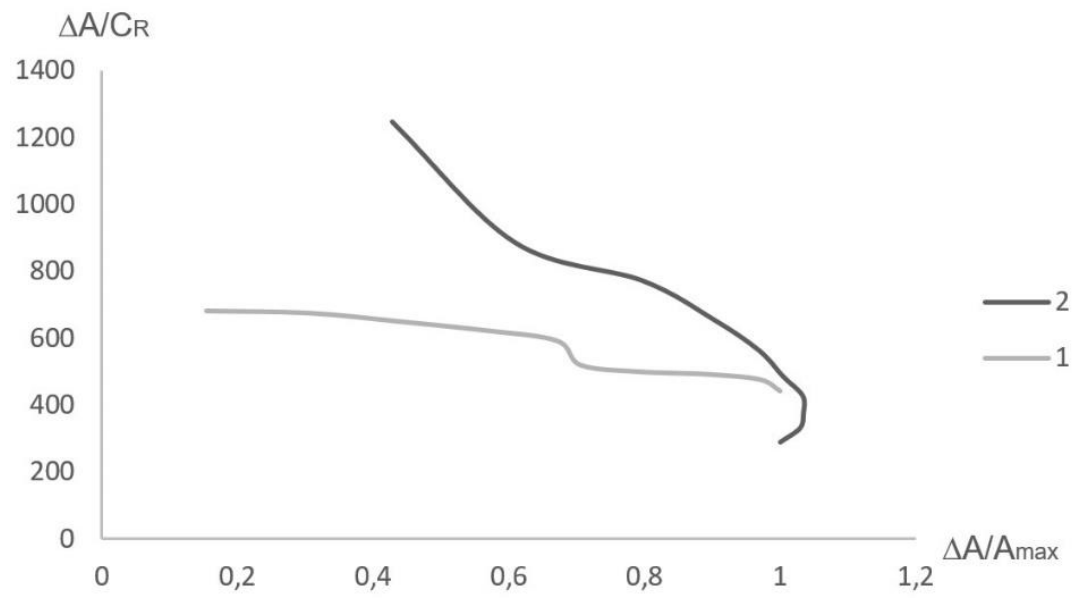

Fig. 4. Curves of the relative yield of "lamotrigine - diazole red $2 \mathrm{~J}$ " reaction product: 1 - at a constant concentration of diazole red $2 \mathrm{~J}(1.00 \mathrm{ml}$ of $0.001 \mathrm{M}$ solution $) ; 2$ - at a constant concentration of lamotrigine

( $1.00 \mathrm{ml}$ of $0.001 \mathrm{M}$ solution) at $\lambda_{\max }=370 \mathrm{~nm}$

Based on the results of the abovementioned methods, stoichiometric ratios of the reacting components were defined, which are unambiguously consistent with each other and are 1:1.

\section{Validation of the technique}

At the stage of confirming the applicability of the developed techniques, to assess the quality of the analyzed substance, validation was performed according to the requirements of the State Pharmacopoeia of Ukraine (SPhU) [19]. Thus, linearity, application range, precision, correctness and robustness were studied.

The determination of linearity, precision and correctness was performed in normalized coordinates, according to the SPhU recommendations for the method of standard [19].

In the range of concentrations in which the subordination to Behr's law is observed, the linearity of the developed technique was defined.

Solutions with a known concentration obtained by diluting a standard solution of lamotrigine were determined by the above-mentioned general technique. Based on the obtained data, we plotted the graph for the dependence of absorption on the analyzed substance concentration and calculated the linear dependence indicators, as shown in Table 1.
Table 1

Parameters of linear dependence

\begin{tabular}{|c|c|c|}
\hline Values & $\begin{array}{c}\text { Criteria (for } 90-110 \% \\
\text { tolerances) }\end{array}$ & $\begin{array}{c}\text { Amount and con- } \\
\text { clusion }\end{array}$ \\
\hline$r$ & $\geq 0.9536$ & $\begin{array}{c}1.000 \\
\text { Corresponds }\end{array}$ \\
\hline$a$ & $\mathrm{a} \leq \mathrm{t}(95 \%, 7) \cdot \mathrm{S}_{\mathrm{a}}=1.89 \cdot \mathrm{S}_{\mathrm{a}}$ & $\begin{array}{c}|0.2567| \\
0.2567 \mid \leq 0.2626 \\
\text { Corresponds }\end{array}$ \\
\hline$b$ & - & 1.003 \\
\hline$S_{a}$ & - & 0.1386 \\
\hline$S_{b}$ & - & 0.0015 \\
\hline$S_{x, 0}(\%)$ & 0.06891 & Corresponds \\
\hline
\end{tabular}

The numerical indicators of linear dependence obtained according to SPhU show that all the requirements for linear dependence parameters are met, i.e., the linearity of the technique is confirmed in the whole range of selected concentrations [20].

Determining the limit of detection (LOD) and the limit of quantification $(L O Q)$.

LOD and LOQ values were calculated based on the value of the standard deviation of the intercept term in the calibration graph equation $\left(S_{a}\right)$ according to the 
formulas: $\mathrm{LOD}=3,3 \cdot S_{a} / b, \quad \mathrm{LOQ}=10 \cdot S_{a} / b$ and were $0.00450 \%$ and $0.0138 \%$ respectively.

The application range was defined when studying linearity. It was proved that the operating range of concentrations is not less than the minimum allowable range of application of spectrophotometric techniques and is $79-121 \%$.

The precision was defined at the level of convergence. According to the developed technique, nine determinations were performed for each of the pharmaceutical forms, within the entire range of application (three concentrations / three determinations for each). The ab- sorbance of the reference solution was measured simultaneously.

Based on the quantitative content results calculated by generally accepted formulae and changed into normalized coordinates, the average value $(\bar{Z} \%)$, the relative standard deviation $\left(S_{Z}, \%\right)$ and the relative confidence interval $(\Delta \%)$ were defined. Based on the data presented in Table 2, in all cases, the one-sided confidence interval does not exceed the maximum allowable uncertainty of the analysis $(\triangle A s \%)$, so the techniques are accurate at the level of convergence, in accordance with the SPhU requirements [19].

Table 2

Determining the precision of the techniques

\begin{tabular}{|l|c|c|c|c|}
\hline \multicolumn{1}{|c|}{ Pharmaceutical form } & $\bar{Z} \%$ & $\mathrm{~S}_{\mathrm{Z}}, \%$ & $\Delta \%$ & $\Delta A s \%$ \\
\hline "Epileptal" 0.05 g (Farmak, Ukraine) & 99.6 & 0.490 & 0.911 & 3.20 \\
\hline "Epileptal" 0.1 g (Farmak, Ukraine) & 99.3 & 0.617 & 1.15 & 3.20 \\
\hline "Lamotrin" 0.1 g (Acino, Switzerland) & 99.5 & 1.19 & 2.22 & 3.20 \\
\hline "Lamictal" 0.1 g (GSK, Great Britain) & 100.8 & 0.652 & 1.21 & 3.20 \\
\hline
\end{tabular}

Intra-laboratory precision.

Defining intra-laboratory precision for the techniques in the "method of standard" variant using the "confirmatory" approach implies that the confidence interval $\left(\Delta_{\text {intra }} \%\right)$ of normalized values obtained in different conditions should not exceed the maximum allowable uncertainty of the analysis technique $(\Delta A s \%)$.

For this, 5 samples of the same series of the investigated "Lamotrin" $0.1 \mathrm{~g}$ pharmaceutical drug (Acino, Switzerland) were analyzed on 3 different days according to the developed technique. The studies were performed by different analysts using different glassware and cuvettes. All the obtained data belong to the same population [20].

As shown in Table 3, intra-laboratory precision of the analysis results is confirmed by the fact that the value of the relative confidence interval (1.60) for five parallel determinations of one series of the pharmaceutical drug on 3 different days satisfies the criterion of acceptance $(\leq 3.20)$.

Table 3

The results of testing the intra-laboratory precision for lamotrigine in "Lamotrin", $0.1 \mathrm{~g}$ tablets

\begin{tabular}{|l|c|c|c|}
\hline \multicolumn{2}{|c|}{ Solution No. } & \multicolumn{3}{|c|}{$\mathrm{Z}_{\mathrm{i}}$ value, $\%$} \\
\cline { 2 - 4 } & 1 analyst & 2 analyst & 3 analyst \\
\hline 1 & 98.09 & 99.11 & 100.0 \\
\hline 2 & 98.00 & 98.92 & 99.24 \\
\hline 3 & 100.9 & 99.48 & 100.9 \\
\hline 4 & 99.39 & 99.46 & 99.39 \\
\hline 5 & 100.0 & 100.0 & 98.00 \\
\hline Combined average value $\left(\bar{Z}_{\text {intra }}, \%\right)$ & \multicolumn{3}{|c|}{99.39} \\
\hline Standard deviation $\left(\mathrm{SD}_{\text {Z-intra }} \%\right)$ & \multicolumn{3}{|c|}{0.9089} \\
\hline Relative confidence interval $\left(\Delta_{\text {intra }} \%\right)$ & 3.60 \\
\hline Critical value of convergence of results $(\Delta A s \%)$ & 3.20 \\
\hline
\end{tabular}

The accuracy was defined by the method of additives, during which different amounts of standard solution of lamotrigine were added to three equal samples of the pharmaceutical form solution and analyzed three times (for each of the four pharmaceutical forms).

According to SPhU, determination results are correct if they are not burdened with significant systematic error, i.e., the true amount of the value being determined falls within the defined confidence interval. Therefore, the proposed techniques for 3 pharmaceutical forms ("Epileptal" 0.05 g, "Lamotrin" $0.1 \mathrm{~g}$ and "Lamictal" $0.1 \mathrm{~g}$ ) are correct, because, as can be seen from Table 4 , the systematic error $\delta_{\text {tot }}$ does not exceed the criterion of insignificance $\delta_{\text {tot }} \leq \Delta \% / 3$, so the techniques are correct [18, 19]. In the case of the "Epileptal" $0.1 \mathrm{~g}$ pharmaceutical form, the criterion of systematic error is not met $\left(\delta_{\text {tot }} \leq \Delta \% / 3\right)$, so we used $\delta_{\text {tot }} \leq \max \delta_{\text {tot }}$ criterion, where $\max$ $\delta_{\text {tot }}=1.024(\mathrm{~B}=10 \%)$, so the technique is still correct [20]. 
Determining the correctness of techniques

\begin{tabular}{|l|c|c|c|c|}
\hline \multicolumn{1}{|c|}{ Pharmaceutical form } & $\bar{Z} \%$ & $\mathrm{~S}_{\mathrm{Z}}, \%$ & $\Delta \%$ & $\delta_{\text {tot }}$ \\
\hline "Epileptal" 0.05 g (Farmak, Ukraine) & 99.5 & 1.67 & 3.10 & 0.450 \\
\hline "Epileptal" 0.1 g (Farmak, Ukraine) & 100.1 & 0.288 & 0.178 & 0.160 \\
\hline "Lamotrin" 0.1 g (Acino, Switzerland) & 99.2 & 0.833 & 1.55 & 0.780 \\
\hline "Lamictal" 0.1 g (GSK, Great Britain) & 100.5 & 1.65 & 3.06 & 0.500 \\
\hline
\end{tabular}

The robustness assessment was performed at the stage of technique development, and the stability of analytical solutions over time was determined, as well as the influence of the amount of added reagents on the determination results. It was found that the studied colored solutions are stable for at least $60 \mathrm{~min}$ (provided the cuvette is tightly closed during the measurement of absorption), and fluctuations in the amount of added reagent (red diazole $2 \mathrm{~J}$ solution) within $\pm 10 \%$ do not significantly affect the value of optical density.

Complete uncertainty of analytical technique

Techniques of quantitative analysis, like all other analytical techniques, must be substantiated and ensured metrologically. The metrological substantiation of a particular analytical technique means that its uncertainty is acceptable for solving tasks at hand. If this is not met, then such uncertainty significantly affects making decisions on the quality of the pharmaceutical drug being analyzed. This means that different results may be obtained in different laboratories, which do not differ statis- tically, but will lead to different conclusions about quality [20].

To assess the correctness of reproducing the developed technique in other laboratories, a forecast for complete uncertainty of the results of the indicated quantitative determination method was made. Its value should be less than the maximum allowable uncertainty $(\max \Delta A s)$.

The formula for calculating the forecast of complete uncertainty is presented below.

$$
\Delta A_{s}=\sqrt{\Delta_{S P}^{2}+\Delta_{F A O}^{2}}
$$

where $\Delta_{S P}$ is uncertainty of sample preparation of the technique; $\Delta_{F A O}$ is predicted uncertainty of the final analytical operation $(0.70 \%$ for spectrophotometry in the visible region of the spectrum).

The forecast for the uncertainty of sample preparation $\left(\Delta_{S P}\right)$ for determining the content of lamotrigine is presented in Table 5.

Table 5

Forecast for uncertainty of sample preparation of the technique

\begin{tabular}{|c|c|c|}
\hline Operation of sample preparation & $\begin{array}{l}\text { Parameter of calcula- } \\
\text { tion formula }\end{array}$ & Uncertainty, \% \\
\hline \multicolumn{3}{|c|}{ Analyzed solution } \\
\hline 1) Taking a weighed portion of tableting mass & $\mathrm{m}_{0}$ & $0.20 \mathrm{mg} / 60 \mathrm{mg} \cdot 100 \%=0.33 \%$ \\
\hline 2) Bringing up to the volume in a $50 \mathrm{ml}$ measuring flask & 50 & $0.17 \%$ \\
\hline 3) Taking an aliquot of dilution with a $1 \mathrm{ml}$ pipette & 1 & $0.74 \%$ \\
\hline 4) Bringing up to the volume in a $10 \mathrm{ml}$ measuring flask & 10 & $0.50 \%$ \\
\hline \multicolumn{3}{|c|}{ Reference solution } \\
\hline 5) Taking a weighed portion & $\mathrm{m}_{0}$ & $0.20 \mathrm{mg} / 14 \mathrm{mg} \cdot 100 \%=1.42 \%$ \\
\hline 6) Bringing up to the volume in a $50 \mathrm{ml}$ measuring flask & 50 & $0.17 \%$ \\
\hline 7) Taking an aliquot with a $1 \mathrm{ml}$ pipette & 1 & $0.74 \%$ \\
\hline 8) Bringing up to the volume in a $10 \mathrm{ml}$ measuring flask & 10 & $0.50 \%$ \\
\hline \multicolumn{3}{|c|}{ Reagent solution } \\
\hline 9) Taking a weighed portion & $\mathrm{m}_{0}$ & $0.20 \mathrm{mg} / 70 \mathrm{mg} \cdot 100 \%=0.28 \%$ \\
\hline $\begin{array}{l}\text { 10) Bringing up to the volume in a } 100 \mathrm{ml} \text { measuring } \\
\text { flask }\end{array}$ & 100 & $0.12 \%$ \\
\hline 11) Taking an aliquot with a $1 \mathrm{ml}$ pipette & 1 & $0.74 \%$ \\
\hline $.33^{2}+0.17^{2} \cdot 2+1.42^{2}+0$ & $2^{2}+0.74^{2} \cdot 3+$ & $=2.1 \%$ \\
\hline
\end{tabular}

By the way, having analyzed Table 5 , it is seen that the most significant uncertainty is introduced into sample preparation by operations 5 - taking a weighed portion of standard sample to prepare reference solution, 3, 7 and $11-$ taking aliquots with $1.00 \mathrm{ml}$ pipettes, as well as 4 and 8 bringing up to the volume in $10.00 \mathrm{ml}$ measuring flasks. Introducing uncertainty to sample preparation with operation 5 is associated with low concentration of reference solution of the standard sample $(0.028 \%)$ and high sensitivity of reaction of interaction with reagent solution in general. Regarding the contribution of the other operations listed above, such distribution of sample preparation uncertainty is quite typical and acceptable for quantitative determination of pharmaceutical drugs.

$$
\Delta_{A_{S}}=\sqrt{\Delta_{S P}^{2}+\Delta_{F A O}^{2}}=\sqrt{2.1^{2}+0.70^{2}}=2.2 \% .
$$

Therefore, the predicted complete uncertainty of the results of analysis for quantitative determination of lamotrigine in the pharmaceutical form $(2.2 \%)$ does not exceed the maximum allowable uncertainty for the technique $(3.2 \%)$ and meets the $\mathrm{SPhU}$ requirements. 


\section{Discussion}

Summarizing the literature data reviews on the analysis methods of lamotrigine in biological samples and pharmaceutical dosage forms, it can be argued that the presented spectrophotometric methods for determination in UV and visible spectrum usually require increasing selectivity [12] or are based on reactions which require special conditions and additional procedures such as extraction [14], $\mathrm{pH}$ control, etc.

For example, a spectrophotometric method is similar in technical essence and achieved results. It consists in dissolving the precisely weighed amount of the tablet weight of lamotrigine in $0.1 \mathrm{M} \mathrm{NaOH}$ solution using an ultrasonic bath for $20 \mathrm{~min}$, stirring, filtering and measuring the absorption in the ultraviolet range of the spectrum at $307 \mathrm{~nm}$ [12]. However, low sensitivity (molar absorption rate is 2848 $1 / \mathrm{mol} \cdot \mathrm{cm}$ ) and selectivity are the significant disadvantages of this method. The proposed method allows to increase the sensitivity (molar absorption rate is $7838 \mathrm{l} / \mathrm{mol} \cdot \mathrm{cm}$ ) and selectivity of the analysis of lamotrigine several times.

The accuracy and selectivity of chromatographic methods $[2,8]$ is not in doubt, but the sustained sample preparation stage, high cost of equipment and consumables reduce their availability. Therefore, the development of direct, non-extractive, selective and sensitive spectrophotometric method for the quantitative determination of lamotrigine in pills is certainly a promising area for improving the quality control of pharmaceutical drugs.

The exclusively use of acetone solutions, in terms of "green chemistry", is a disadvantage of the developed method, so it would be more rational to use aqueous or aqueous-organic solvents, taking into account the solubility of the interacting products.

Study limitations. The previously developed methodology has been tested only for the quantitative determination of lamotrigine in pharmaceutical forms. Therefore, it is not advisable to use it without prior research in order to analyze lamotrigine in biological fluids.

Prospects for further research. Further, it is also advisable to synthesize, isolate and identify the products of interaction, based on the established stoichiometric relationships between the components in the system "lamotrigine - diazole red 2J".

And of course, it is appropriate to implement the results of the study in practical pharmacy, as well as in the work of the State Service on Medicines and Drugs Control in the regions of Ukraine.

\section{Conclusions}

It was found that lamotrigine interacts with diazole red $2 \mathrm{~J}$ in acetone medium under the condition of keeping the reaction mixture for $15 \mathrm{~min}$ at room temperature. The studied reaction is highly sensitive; the detection boundary is $1.63 \mu \mathrm{g}$.

A sensitive, accessible and affordable technique for lamotrigine analysis has been developed and tested on 4 modern pharmaceutical drugs.

It is proved that the developed technique for quantitative determination, according to such basic validation characteristics as linearity, precision, accuracy, application range and robustness, is characterized by validity, ease of performance, as well as affordability and accessibility, and it can be recommended for quality control of the presented pharmaceutical forms.

The defined coefficients of stoichiometric ratios in the "lamotrigine - diazole red $2 \mathrm{~J}$ " system are 1:1.

The forecast of complete uncertainty of results of the specified quantitative determination method for an estimation of correctness of reproduction of the developed technique in other laboratories is performed. It is proved that the predicted complete uncertainty of the results of the analysis for the quantitative determination of lamotrigine in the pharmaceutical form meets the SPhU requirements and does not exceed the maximum allowable uncertainty of the technique.

\section{Conflict of interests}

The authors declare that they have no conflicts of interest.

\section{Financing}

The study was performed without financial support.

\section{References}

1. British Pharmacopoeia Commission (2016). London: British Pharmacopoeia, TSO.

2. Sabença, R., Bicker, J., Silva, R., Carona, A., Silva, A., Santana, I. et. al. (2021). Development and application of an HPLC-DAD technique for human plasma concentration monitoring of perampanel and lamotrigine in drug-resistant epileptic patients. Journal of Chromatography B, 1162, 122491. doi: http://doi.org/10.1016/j.jchromb.2020.122491

3. Abou-Taleb, N. H., El-Sherbiny, D. T., El-Enany, N. M., El-Subbagh, H. I. (2022). A new grey relational analysis application in analytical chemistry: Natural deep eutectic solvent as a green extractant for HPLC determination of lamotrigine in plasma. Microchemical Journal, 172. doi: http://doi.org/10.1016/j.microc.2021.106918

4. Croci, D., Salmaggi, A., de Grazia, U., Bernardi, G. (2001). New High-Performance Liquid Chromatographic Method for Plasma/Serum Analysis of Lamotrigine. Therapeutic Drug Monitoring, 23 (6), 665-668. doi: http://doi.org/10.1097/00007691200112000-00012

5. Torra, M., Rodamilans, M., Arroyo, S., Corbella, J. (2000). Optimized Procedure for Lamotrigine Analysis in Serum by High-Performance Liquid Chromatography Without Interferences From Other Frequently Coadministered Anticonvulsants. Therapeutic Drug Monitoring, 22 (5), 621-625. doi: http://doi.org/10.1097/00007691-200010000-00019

6. Ventura, S., Rodrigues, M., Pousinho, S., Falcão, A., Alves, G. (2016). An easy-to-use liquid chromatography assay for the analysis of lamotrigine in rat plasma and brain samples using microextraction by packed sorbent: Application to a pharmacokinetic study. Journal of Chromatography B, 1035, 67-75. doi: http://doi.org/10.1016/j.jchromb.2016.09.032

7. Abou-Taleb, N. H., El-Sherbiny, D. T., El-Enany, N. M., El-Subbagh, H. I. (2020). Multiobjective optimization of microemulsion- thin layer chromatography with image processing as analytical platform for determination of drugs in plasma using desirability functions. Journal of Chromatography A, 1619. doi: http://doi.org/10.1016/j.chroma.2020.460945

8. Nikolaou, P., Papoutsis, I., Dona, A., Spiliopoulou, C., Athanaselis, S. (2015). Development and validation of a GC/MS method for the simultaneous determination of levetiracetam and lamotrigine in whole blood. Journal of Pharmaceutical and Biomedical Analysis, 102, 25-32. doi: http://doi.org/10.1016/j.jpba.2014.08.034 
9. Theurillat, R., Kuhn, M., Thormann, W. (2002). Therapeutic drug monitoring of lamotrigine using capillary electrophoresis. Journal of Chromatography A, 979 (1-2), 353-368. doi: http://doi.org/10.1016/s0021-9673(02)01257-8

10. Greiner-Sosanko, E., Giannoutsos, S., Lower, D. R., Virji, M. A., Krasowski, M. D. (2007). Drug Monitoring: Simultaneous Analysis of Lamotrigine, Oxcarbazepine, 10-Hydroxycarbazepine, and Zonisamide by HPLC-UV and a Rapid GC Method Using a Nitrogen-Phosphorus Detector for Levetiracetam. Journal of Chromatographic Science, 45 (9), 616-622. doi: http://doi.org/10.1093/chromsci/45.9.616

11. Abou-Taleb, N. H., El-Enany, N. M., El-Sherbiny, D. T., El-Subbagh, H. I. (2021). Spider diagram and Analytical GREEnness metric approach for assessing the greenness of quantitative 1H-NMR determination of lamotrigine: Taguchi method based optimization. Chemometrics and Intelligent Laboratory Systems, 209. doi: http://doi.org/10.1016/j.chemolab.2020.104198

12. Rajendraprasad, N., Basavaiah, K. (2012). Simple and Sensitive Spectrophotmetric Determination of Lamotrigine in Pure Form and in Dosage Forms. Pharmaceutica Analytica Acta, 3 (9). doi: http://doi.org/10.4172/2153-2435.1000188

13. Biscaia, I., Todeschini, V., de Meira, R., Nogueira, C., Bernardi, L., de Oliveira, P. (2020). Development of a First-Order Derivative UV Spectrophotometric Method for the Assay and Solubility Evaluation of Lamotrigine and Nicotinamide Cocrystals. Journal of the Brazilian Chemical Society, 31 (12), 2561-2568. doi: http://doi.org/10.21577/0103-5053.20200134

14. Heidari, H., Mammostafaei, C. (2021). Spectrophotometric determination of lamotrigine in plasma samples: Ultrasoundassisted emulsification-microextraction based on a hydrophobic deep eutectic solvent followed by back-extraction. Spectrochimica Acta Part A: Molecular and Biomolecular Spectroscopy, 247. doi: http://doi.org/10.1016/j.saa.2020.119098

15. Rajendraprasad, N., Basavaiah, K., Vinay, K. B. (2010). Sensitive spectrophotometric determination of lamotrigine in bulk drug and pharmaceutical formulations using bromocresol green. Eclética Química, 35 (1), 55-66. doi: http://doi.org/10.1590/s010046702010000100007

16. Rajendraprasad, N., Basavaiah, K., Vinay, K. B. (2010). Micro and nanogram determination of lamotrigine in pharmaceuticals by visible spectrophotometry using bromophenol blue. Indian Journal of Chemical Technology, 17 (3), $220-228$.

17. Jayanna, B. K., Devaraj, T. D. (2016). Spectrophotometric Estimation of Lamotrigine in Tablets. Indian Journal of Pharmaceutical Sciences, 78 (5), 657-662. doi: http://doi.org/10.4172/pharmaceutical-sciences.1000165

18. Bulatov, M. I., Kalinkin, I. P. (1986). Prakticheskoe rukovodstvo po fotometricheskim metodam analiza. Leningrad: Himiya, 432.

19. Derzhavna Farmakopeia Ukrainy. Vol. 1 (2015). Kharkiv: Derzhavne pidpryiemstvo «Ukrainskyi naukovyi farmakopeinyi tsentr yakosti likarskykh zasobiv», 1128.

20. Grisodub, A. I. (2016). Standartizovannyye protsedury validatsii metodik kontrolya kachestva lekarstvennykh sredstv. Kharkiv: Derzhavne pidpryiemstvo «Ukrainskyi naukovyi farmakopeinyi tsentr yakosti likarskykh zasobiv», 396.

Received date 16.12.2021

Accepted date 22.02.2022

Published date 28.02.2022

Kateryna Miedviedieva*, PhD, Associate Professor, Department of Analytical Chemistry, Zaporizhzhia State Medical University, Maiakovskoho ave., 26, Zaporizhzhia, Ukraine, 69035

Svitlana Vasyuk, Doctor of Pharmaceutical Sciences, Professor, Department of Analytical Chemistry, Zaporizhzhia State Medical University, Maiakovskoho ave., 26, Zaporizhzhia, Ukraine, 69035

Alla Korzhova, PhD, Associate Professor, Department of Analytical Chemistry, Zaporizhzhia State Medical University, Maiakovskoho ave., 26, Zaporizhzhia, Ukraine, 69035

Ivan Pavljuk, PhD, Senior Forensic Expert, Zaporizhzhia Research Forensic Center of the Ministry of Internal Affairs of Ukraine, Avaliani str., 19a, Zaporizhzhia, Ukraine, 69068

*Corresponding author: Kateryna Miedviedieva, e-mail: kate-portnaya@ukr.net 